\title{
Morphine abuse and bilateral digital ischemia
}

\section{Phillippe Leclercq MD, Bernard Lambermont MD}

Previously published at www.cmaj.ca

$\mathrm{A}$ 44-year-old man presented to the emergency department with a two-day history of redness and pain in the fingers of both hands (Figure 1A). An intravenous morphine user, he had been injecting morphine bilaterally with the help of a partner for the past six months. The pain in his fingers had started shortly after his most recent injection.

On examination, the patient had thrills over the scars of the brachial injection sites (Figure 1B). His radial pulses were normal and he had a blood pressure of 160/80 $\mathrm{mm} \mathrm{Hg}$. Echocardiography was normal. Arteriography of his upper limbs showed distal embolization in the fingers and bilateral brachial pseudoaneurysms (Figure 1C).

The pseudoaneurysms may have been caused by repeated punctures of the patient's brachial arteries. Drug-related endothelial injury may have led to platelet activation and associated localized thrombosis. ${ }^{1,2}$ Particulate emboli (e.g., talc used to dilute injected morphine), may have also contributed to the ischemia. Our patient's digital ischemia improved markedly following resection of his pseudoaneurysms and digital sympathectomy. 3.4

\section{REFERENCES}

1. Wahlgren CM, Lohman R, Pearce BJ, et al. Metachronous giant brachial artery pseudoaneurysms: a case report and review of the literature. Vasc Endovascular Surg 2007;41:467-72.

2. Becquemin JP, Etienne G, Schaeffer A, et al. Acute ischemia of the extremities and drug addiction. J Mal Vasc 1986;11:35-8.

3. Siu WT, Yau KK, Cheung HY, et al. Management of brachial artery pseudoaneurysms secondary to drug abuse. Ann Vasc Surg 2005;19:657-61.

4. Pollock DC, Li Z, Rosencrance E, et al. Acute effects of periarterial sympathectomy on the cutaneous microcirculation. J Orthop Res 1997;15:408-13.

From the Department of Gastroenterology (Leclercq) and the Intensive Care Unit (Lambermont) of the Centre Hospitalier Universitaire de Liège, Hôpital du Sart-Tilman, Liège, Belgium

Cite as CMAJ 2009. DOI:10.1503/cmaj.081281

Clinical images are chosen because they are particularly intriguing, classic or dramatic. Submissions of clear, appropriately labelled high-resolution images must be accompanied by a figure caption and the patient's written consent for publication. A brief explanation (300 words maximum) of the educational significance of the images with minimal references is required.

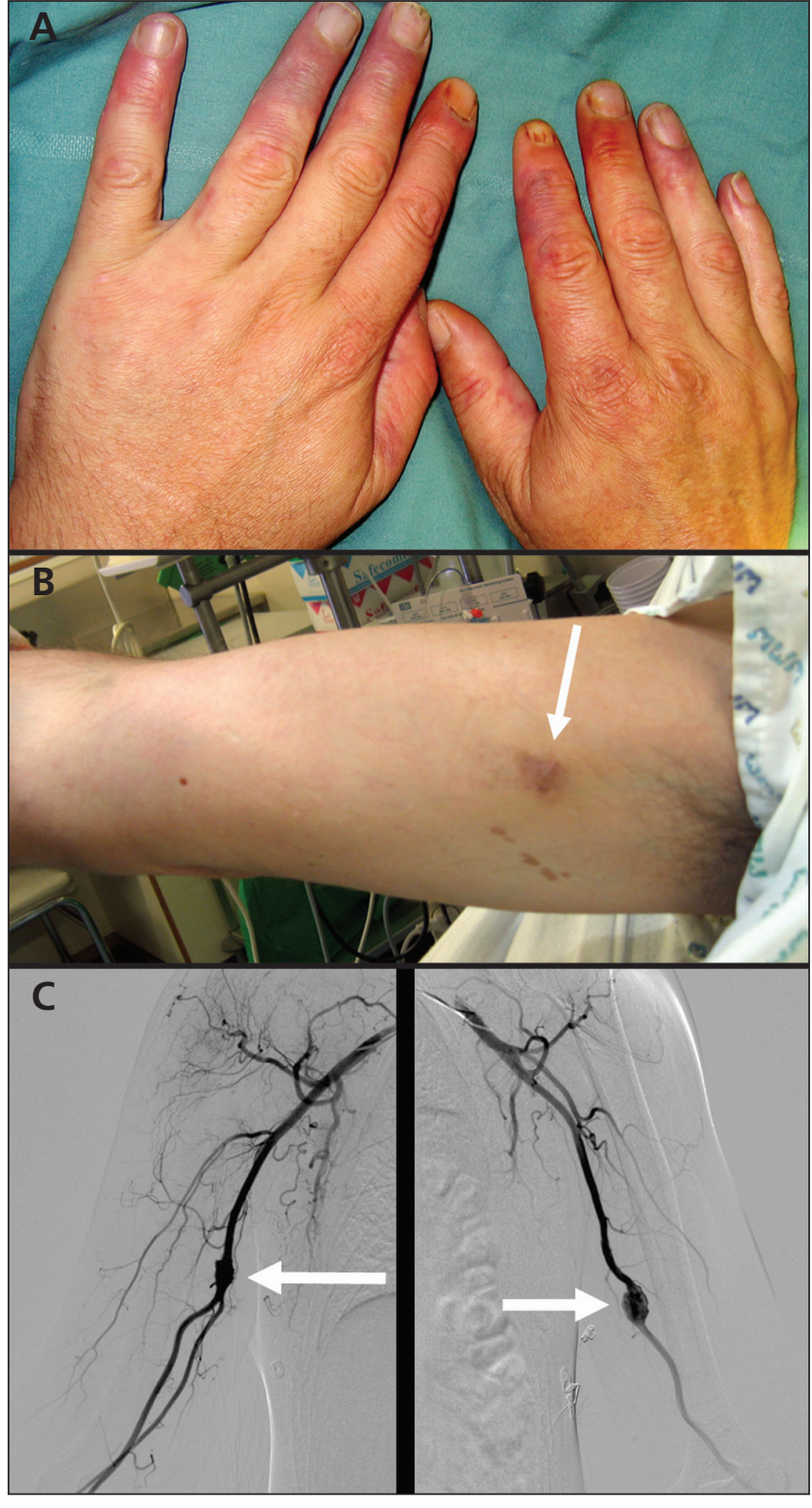

Figure 1: Photographs show $(A)$ bilateral redness of the fingers and (B) brachial injection sites on the arm of a 44-year-old man with a history of intravenous use of morphine. (C) Angiography in both arms shows bilateral brachial pseudoaneurysms (arrows). 